\title{
Identificación molecular por PCR del gusano cogollero en el Sur del Ecuador
}

\section{Molecular identification by PCR of the armyworm in southern Ecuador}

\author{
Patricio Castro-Quezada ${ }^{1}$ (D), Norma Quillay-Curay ${ }^{2}$,Catalina Bravo-Zúñiga ${ }^{2}$ \\ 1 Facultad de Ciencias Agropecuarias, Universidad de Cuenca, Cuenca, Ecuador. \\ 2 Instituto Nacional de Investigaciones Agropecuarias (INIAP), Estación Experimental del Austro. Laboratorio de \\ Protección Vegetal, Km 12 1/2 Vía a El Descanso - Gualaceo sector Bullcay, Provincia Azuay, Cantón Gualaceo. \\ Autor para correspondencia: patricio.castro@ucuenca.edu.ec \\ Fecha de recepción: 12 de febrero de 2019 - Fecha de aceptación: 11 de abril de 2019
}

\section{RESUMEN}

Spodoptera frugiperda es un insecto considerado como una plaga primaria de cultivos de maíz. Esta especie polífaga, incluida en el grupo de los comúnmente conocidos como gusanos cogolleros, es considerada una plaga, de efectos económicos de importancia, en varios países del continente americano. En el maíz, estas larvas causan daños desde el estado de plántula hasta la etapa de pre-madurez. Sin embargo, la identificación de los lepidópteros normalmente se realiza en base a la morfología de los adultos y, por lo tanto, las larvas tienen que criarse hasta el estado adulto para su identificación. Actualmente, el uso de herramientas moleculares como la PCR, basada en secuencias de ADN mitocondrial o nuclear, son utilizadas para identificación inequívoca de plagas o biotipos a partir de larvas. El objetivo de esta investigación fue identificar, a nivel molecular por análisis de PCR, la presencia de la especie $S$. frugiperda en cultivos de maíz blanco en el Sur del Ecuador. Para el efecto se colectaron un total de 360 larvas en 36 sitios distribuidos en tres provincias: 18 en Azuay, 12 en Cañar y 6 en Loja, entre los meses de enero a marzo de 2015. La identificación molecular se realizó con primers específicos para S. frugiperda a nivel del gen mitocondrial de la subunidad 1 citocromo oxidasa (COI) I. Como resultado se generaron amplificaciones de pesos moleculares de aproximadamente $500 \mathrm{pb}$ correspondientes a $S$. frugiperda. Esta caracterización molecular es, a nuestro conocimiento, la primera que se realiza para el Austro del Ecuador.

Palabras clave: Maíz blanco, citocromo oxidasa, caracterización molecular.

\begin{abstract}
Spodoptera frugiperda is an insect pest of corn. This polyphagous species is included within the group of the armyworms, considered pests of economic importance in several countries of America. In corn, these larvae cause damage from the seedling to pre-ripeness stages. Identification of Lepidoptera is usually based on the morphology of adults, meaning that larvae must reach adulthood for their identification. Nevertheless, the larval period is the stage that causes mayor damage in corn. Currently, the use of molecular tools such as PCR, based on mitochondrial or nuclear DNA sequences, has been used for unambiguous identification of pests or biotypes from larvae. The objective of this study was to identify the presence of $S$. frugiperda species in white corn crops in the South of Ecuador at molecular level. For this, we used a PCR analysis with specific primers for $S$. frugiperda at the level of the mitochondrial gene of subunit 1 cytochrome oxidase (COI) I. A total of 360 larvae were collected in 36 sites distributed in three provinces: 18 in Azuay, 12 in Cañar and 6 in Loja, between January and March 2015. As a result, amplifications of molecular weights of approximately $500 \mathrm{pb}$ corresponding to $S$. frugiperda were generated. This molecular characterization is, to our knowledge, the first one performed for the Austro of Ecuador.
\end{abstract}

Keywords: White corn, cytochrome oxidase, molecular characterization.

\section{INTRODUCTION}

El género Spodoptera Guenée, 1852 (Noctuidae: Amphipyrinae) está compuesto por un grupo de especies de polillas-plagas de gran impacto económico. La mayoría de sus especies se encuentran distribuidas en el hemisferio occidental (Pogue, 2002). Dentro del género, estas plagas representan "especies crípticas" debido a que su morfología externa es muy similar a nivel de larva y adulto. Entre las especies más conocidas en el continente americano se encuentran: Spodoptera frugiperda (J.E. Smith), Spodoptera ornithogalli (Guenee), Spodoptera albula (Walker), Spodoptera exigua (Hübner), Spodoptera eridania (Stoll), Spodoptera androgea (Stoll), Spodoptera latifascia (Walker), Spodoptera dolichos (Fabricius), Spodoptera pulchella (Herrich-Schäffer) (Brown \& Dewhurst, 1975).

S. frugiperda es una plaga polífaga nativa del hemisferio occidental, en donde está ampliamente distribuida en zonas tropicales y subtropicales (Álvarez, 1991; Pastrana \& Hernández, 1979). Esta especie está considerada como plaga primaria en el cultivo de maíz, pero también pueden atacar cultivos de algodón, sorgo, arroz, pastos y maní, entre otros (Sparks, 1979; Pogue, 2002; Murua \& Virla, 
2004). En Brasil, por ejemplo, S. frugiperda está considerada como una peste mayor ya que puede causar un $34 \%$ de reducción de la cosecha de maíz (Lima, Silva, Oliveira, Silva, \& Freitas, 2010).

El maíz es un cultivo considerado importante para la seguridad alimentaria del Ecuador (Valarezo, Cañarte, Navarrete, \& Muñoz, 2010). El maíz blanco se cultiva en el Ecuador para autoconsumo familiar o para el mercado interno nacional. Este tipo de maíz es cultivado en toda la Sierra del Ecuador (Bravo \& León, 2013). De acuerdo a Instituto Nacional Autónomo de Investigaciones Agropecuarias - INIAP (2011), en el Austro se siembra un maíz blanco semiduro, comúnmente conocido como maíz zhima. En el año 2017, en el Austro, se reportaron 11,100 ha sembradas de maíz blanco (INEC, 2017).

En Ecuador, el gusano cogollero "Spodoptera" también causa grandes pérdidas económicas; en el litoral ecuatoriano se estima que ataques severos de este lepidóptero (sobre el $20 \%$ de infestación) puede reducir entre un 10 y $60 \%$ el rendimiento de otra variedad de maíz: el maíz duro, también conocido como maíz amarillo (Valarezo et al., 2010). Los autores desconocen la existencia de registros sobre el nivel de daño de esta plaga para el maíz blanco. Para el control de esta plaga, el de tipo químico es el más empleado. Sin embargo, este tipo de control causa efectos adversos sobre las poblaciones de organismos no perjudiciales para este cultivo. Además, el uso excesivo puede favorecer el desarrollo de resistencia a esta plaga (Chandler \& Sumner, 1991).

El ADN mitocondrial de Lepidoptera ha sido usado en estudios de genética de poblaciones y filogenia (Weller \& Pashley 1994; Lunt, Zhang, Szymura, \& Hewitt 1996). Primers universales han sido diseñados para amplificar la región del gen mitocondrial de la subunidad 1 del citocromo oxidasa (COI) del ADN, usando la Reacción en Cadena de la Polimerasa (PCR) (Kambhampati \& Smith 1995). Así, diferentes estudios de análisis moleculares han permitido identificar el biotipo de la especie responsable de los daños causados en maíz, con el uso de primers específicos (Sambrook \& Rusell 2001; Levy, GarcíaMaruniak \& Maruniak, 2002).

Estudios realizados en Colombia han identificado la presencia de dos biotipos, uno del maíz y otro del arroz, prácticamente idénticos en su morfología, pero diferentes en su composición genética y en su resistencia hacia insecticidas y a Bacillus thuringiensis, siendo el biotipo de maíz, con respecto al biotipo de arroz, más resistente. Los dos biotipos son morfológicamente idénticos, pero diferenciables mediante el uso de códigos de barras de ADN. Usualmente, la identificación del biotipo del maíz utiliza una PCR-RFLP a nivel del gen mitocondrial citocromo oxidasa I; para la identificación del biotipo del arroz, se utiliza una PCR de la región tandem FR del ADN nuclear (Vélez-Arango, Arango, Villanueva, Aguilera, \& Saldamando, 2008). Los mencionados métodos moleculares han permitido detectar la presencia de $S$. frugiperda fuera del continente americano. Cock, Beseh, Buddie, Cafá, \& Crozier (2017) identificaron la presencia de $S$. frugiperda en Ghana a partir de primers definidos para la subunidad 1 del citocromo oxidasa $\mathrm{C}$.

En el Ecuador no existen estudios de identificación de los biotipos presentes, ni tampoco se han realizado estudios a nivel molecular para determinar la especie responsable de los daños ocasionados en el maíz por el comúnmente denominado "gusano cogollero". El presente trabajo tiene como objetivo confirmar, mediante el uso de PCR, la presencia de $S$. frugiperda en maíz blanco, especie comúnmente considerada como plaga en cultivos de otras variedades de maíz.

\section{MATERIALES Y MÉTODOS}

\subsection{Ubicación geográfica}

La recolección de muestras se realizó en 36 sitios distribuidos en las provincias de Azuay, Cañar y Loja en el sur del Ecuador en cultivos cuya edad promedio fue de 2.5 meses, en pisos altitudinales que van desde 1,439 a $2,932 \mathrm{msnm}$.

\subsection{Muestreo}

En cada sitio, por provincia, se recolectaron larvas en lotes con cultivo de maíz, utilizando la metodología de monitoreo de la PIONEER (2014) modificada, cubriendo cada lote en 5 estaciones de muestreo en forma de " $\mathrm{X}$ " $\mathrm{y}$ tomando, en cada estación, 2 plantas con síntomas de daño, 10 plantas por lote. Las larvas recolectadas correspondieron mayoritariamente a estados L4 (11-15 mm), L5 (15-20 mm) y L6 (> $20 \mathrm{~mm}$ ) (Fig.1), en todos los sitios de muestreo, localizados en las provincias de Azuay, Cañar y Loja. Las larvas recolectadas fueron conservadas en alcohol al $95 \%$ en tubos de ensayo de $100 \mathrm{ml}$ con tapa hermética, estos se trasladaron al Laboratorio de Biotecnología de la Universidad de Cuenca, Facultad de Ciencias Agropecuarias, para su caracterización molecular.

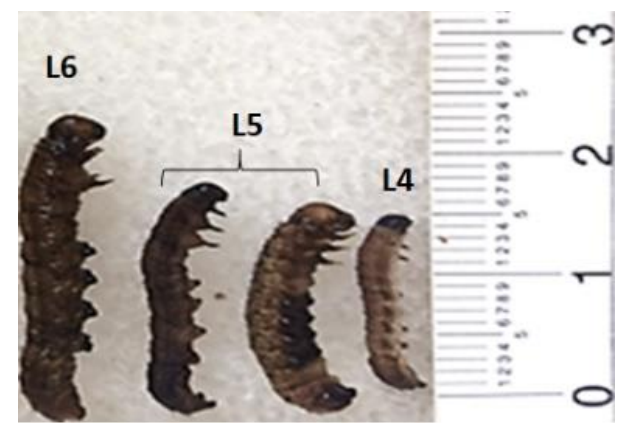

Figura 1. Estados larvarios de Spodoptera spp. (L4, L5 y L6) en $\mathrm{mm}$.

\subsection{Caracterización molecular}

La extracción de ADN genómico se realizó siguiendo el protocolo de Sambrook \& Russell (2001), con algunas modificaciones hechas por Vélez-Arango et al. (2008). Para esto, se empleó la parte posterior del cuerpo de las larvas de segundo a quinto instar y se depositó en un tubo Eppendorf de $1.5 \mathrm{ml}$ al cual se le adicionó $400 \mathrm{ml}$ de buffer de extracción CTAB (2X). Cada tubo se mezcló por medio de un vórtex y se incubó por 30 minutos a $65^{\circ} \mathrm{C}$. Posteriormente, a cada muestra se le adicionó $400 \mathrm{ml}$ de cloroformo-alcohol isoamílico en una proporción 24:1 y se centrifugó por 6 minutos a $13,000 \mathrm{rpm}$ a $4^{\circ} \mathrm{C}$. A continuación, se tomó el sobrenadante en un nuevo tubo y se repitió el procedimiento con un volumen equivalente de cloroformo. El nuevo sobrenadante se transfirió a un tubo y se adicionó un volumen equivalente de isopropanol. 
Después, las muestras se centrifugaron por 6 minutos, el sobrenadante se eliminó y el sedimento restante se lavó con $200 \mathrm{ml}$ de etanol al 70\%, y, a continuación, se centrifugaron por 5 minutos. El sedimento restante se secó al vacío y se resuspendió en $50 \mu \mathrm{l}$ en buffer TE (1X) (TRIS $100 \mathrm{mM}$ y EDTA $10 \mathrm{mM}$, pH ajustado a 8.0 con $\mathrm{HCl}$ ). Finalmente, el ADN fue almacenado a $-20^{\circ} \mathrm{C}$.

Las secuencias de primers utilizados en este estudio se tomaron de acuerdo a lo expuesto por Levy et al. (2002), definidas a partir del gen Citocromo oxidasa $\mathrm{C}$ subunidad 1(COI): JM-76-1 F GAGCTGAATTAGGGACTCCAGG y JM-77-1 R ATCACCTCCACCTGCAGGATC.

Las reacciones de amplificación se realizaron en un termociclador Eppendorf Mastercycler NexusGSX1. Para la reacción se empleó la metodología de Vélez-Arango et al. (2008). El ADN genómico se amplificó en $25 \mu \mathrm{lde}$ mezcla de reacción que contuvo $2.5 \mu \mathrm{l}$ de buffer de Taq polimerasa (10X) (Invitrogen), $1.5 \mathrm{mM}$ de $\mathrm{MgCl}_{2}, 50 \mu \mathrm{M}$ de cada dNTP (dATP, dCTP, dGTP y dTTP) (Invitrogen, California U.S.A), $4 \mu \mathrm{M}$ de cada primer (JM76 F y JM77 $\mathrm{R}), 0.5 \mathrm{U}$ de Taq ADN polimerasa (Invitrogen), $17 \mu \mathrm{lde}$ $\mathrm{H}_{2} 0$ y $50 \mathrm{ng}$ de $\mathrm{ADN}$ genómico como templado. Para la PCR se realizó un ciclo inicial de $94^{\circ} \mathrm{C}$ por 3 minutos, seguido de 30 ciclos a $94^{\circ} \mathrm{C}$ por 1 minuto, $62^{\circ} \mathrm{C}$ por 1 minuto y $72^{\circ} \mathrm{C}$ por 1 minuto, y un ciclo de extensión final de $72^{\circ} \mathrm{C}$ por 10 minutos. Las muestras se analizaron en un gel de agarosa al $1 \%$ con bromuro de etidio $(0.25 \mu \mathrm{g} \mathrm{ml}-$ 1) y se visualizaron en un transluminador UV BioRad.

\section{RESULTADOS Y DISCUSIÓN}

Se recolectaron un total de 360 larvas, mayoritariamente en los cogollos de plantas en etapa de desarrollo vegetativo, con un promedio de edad de 2.5 meses, en 36 sitios distribuidos en las provincias de Azuay (18), Cañar (12) y Loja (6).

La PCR del gen mitocondrial COI produjo una amplificación de un fragmento de aproximadamente 500 pb. (Fig. 2). Se utilizaron los primers JM76F y JM77R, los

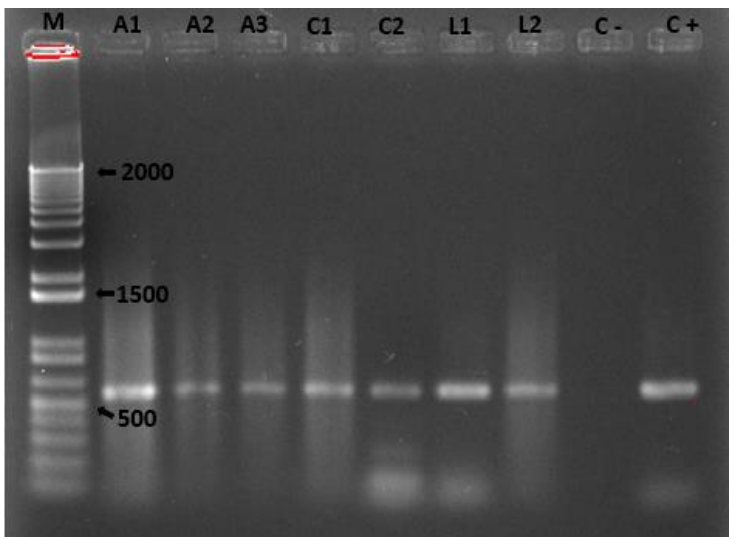

Figura 2. Amplificación de los productos de PCR del gen mitocondrial COI (569 pb) de las larvas de Spodoptera frugiperda. M: Marcador de Peso Molecular; líneas A1, A2 y A3: muestras de Azuay; líneas C1 y C2: muestras de Cañar, líneas L1 y L2: muestras de Loja; C-: control negativo; $\mathrm{C}+$ : control positivo. cuales flanquean la región COI para amplificar un producto de $569 \mathrm{pb}$ en larvas de Spodoptera. A través de un método molecular (PCR) se determinó la presencia de S. frugiperda en maíz blanco.

Los primers utilizados pueden amplificar productos PCR dentro de la región del COI en todos los estadíos de $S$. frugiperda: larvas y adultos (Vélez-Arango et al. 2008). El gen mitocondrial también ha permitido identificar biotipos de $S$. frugiperda en maíz en otros estudios (Levy et al. 2002; Vélez-Arango et al. 2008), dado que ellos obtuvieron también bandas electroforéticas de aproximadamente $560 \mathrm{pb}$. Estudios complementarios, utilizando un marcador PCR-RFLP con la enzima de restricción MspI, han permitido en Colombia discriminar los biotipos de arroz y maíz (Vélez-Arango et al. 2008). Este tipo de análisis por PCR-RFLP ha sido utilizado también para determinar el isotipo de larvas de $S$. frugiperda colectadas en maíz, pasto bermuda y sorgo.

Si bien los marcadores basados en ADN mitocondrial junto con marcadores nucleares se han utilizado preferentemente para identificar biotipos de $S$. frugiperda en arroz y maíz (Vélez-Arango et al. 2008), Cock et al. (2017) utilizaron marcadores moleculares diseñados en el ADN mitocondrial para reportar la presencia de $S$. frugiperda en Ghana. Comparaciones realizadas con BLAST (Basic Local Alignment Search Tool) en la página del NCBI (National Center for Biotechnology Information) muestran que los primers utilizados por Cock et al. (2017) indican valores para E-value comprendidos entre $1 \mathrm{e}-05$ y $2 \mathrm{e}-05$, mientras que los primers utilizados en nuestro estudio presentan valores de $3 \mathrm{e}-05$, considerados más significativos para la especie. Por lo tanto, consideramos que los primers utilizados son válidos para identificar la presencia de $S$. frugiperda como responsable de los daños causados en maíz blanco.

Tradicionalmente, la identificación de los lepidópteros se basa en las características morfológicas de los adultos, y no en las características de su etapa de oruga (Holloway, Bradley, \& Carter, 1987). Cañas-Hoyos, Márquez, \& Saldamando-Benjumea (2014) determinaron que las medidas morfométricas del ala sirven para diferenciar los biotipos del arroz y maíz en Colombia. Sin embargo, en este caso la detección e identificación de la plaga involucra una recolección de orugas, su crianza hasta adultos para facilitar la identificación y, a menudo, la disección del macho y/o los genitales femeninos para confirmar una identificación (Holloway et al. 1987). Este trabajo debe ser realizado por entomólogos experimentados, recurso escaso en nuestro medio y, por lo tanto, para una identificación precisa de la plaga se requiere un método molecular, como el presentado en este estudio. Además, el diagnóstico con la técnica PCR es rápido y fácil porque el ADN necesario para el análisis puede ser amplificado a partir del ADN total sin necesidad de purificarlo (Levy et al. 2002).

Este estudio tiene implicaciones para el diagnóstico y la identificación de plagas en nuestro medio o para la identificación de nuevas especies invasoras que potencialmente podrían ser introducidas en el futuro. En este contexto, particularmente en la región sur del Ecuador, que cuenta con una capacidad limitada para la identificación de plagas mediante la metodología tradicional (i.e., identificación morfo taxonómica) las técnicas moleculares son una alternativa viable de identificación de taxones conocidos. Así, las técnicas moleculares como la PCR, combinadas con el uso de otras 
técnicas como, por ejemplo, la de enzimas de restricción, facilitan la identificación de plagas, como apoyo taxonómico para especies morfológicamente similares, o para aproximaciones a la filogenia de una especie, como ha sido señalado por Saldamando \& Márquez (2012).

\section{CONCLUSIÓN}

Este estudio ha permitido confirmar a nivel molecular la presencia de $S$. frugiperda, especie comúnmente asociada con la destrucción de cogollos en cultivos de maíz. Aun cuando el análisis del nivel de daño producido por esta especie en el maíz cultivado en la serranía ecuatoriana estuvo fuera del alcance de la presente investigación, el presente trabajo presenta una metodología identificación a nivel molecular que servirá de base para la identificación de biotipos y del nivel de presencia, y consecuente afectación, producida por esta u otras especies, consideradas como plagas de cultivos tradicionales de la región. El método presentado facilitará la generación de información, herramienta básica para un adecuado manejo y control integrado de plagas.

\section{REFERENCIAS}

Álvarez, A. (1991). Reseña histórica y aspectos bioecológicos del gusano cogollero del maíz Spodoptera frugiperda (J. E. Smith). In Memorias Seminario Spodoptera frugiperda (El gusano cogollero) en sorgo, maíz y otros cultivos. Zuluaga, J. L. Muñoz, G. (comp., ed.) Calí, Colombia, pp. 12-14.

Bravo, E., \& León, X. (2013). Monitoreo participativo del maíz ecuatoriano para detectar la presencia de proteínas transgénicas. La Granja, 17(1), 16-24.

Brown, E. S., \& Dewhurst, C. F. (1975). The genus Spodoptera (Lepidoptera, Noctuidae) in Africa and the Near East. Bulletin of Entomological Research, 65(2), 221-262. https://doi.org/10.1017/S0007485300005939

Chandler, L. D., \& Sumner, H. R. (1991). Effect of various chemigation methodologies on suppression of the fall armyworm (Lepidoptera: Noctuidae) in corn. The Florida Entomologist, 74(2), 270-279. https://www.doi.org/10.2307/3495306

Cañas-Hoyos, N., Márquez, E. J., \& SaldamandoBenjumea, C. I. (2016). Heritability of wing size and shape of the rice and corn strains of Spodoptera frugiperda (J.E. Smith) (Lepidoptera: Noctuidae). Neotropical Entomology, 45(4), 411-419. https://doi.org/10.1007/s13744-016-0393-y

Cock, M. J. W., Beseh, P. K., Buddie, A. G., Cafá G., \& Crozier, J. (2017). Molecular methods to detect Spodoptera frugiperda in Ghana, and implications for monitoring the spread of invasive species in developing countries. Scientific Reports, 7(1), 4103. htpps://www.doi.org/10.1038/s41598-017-04238-y

Holloway, J.D., Bradley, J. D., \& Carter, D. J. (1987). CIE guides to insects of importance to man - 1 Lepidoptera. CAB International, Wallingford, UK 262 pp.
INEC. (2017). Estadísticas Agropecuarias. Retrieved from http://www.ecuadorencifras.gob.ec/estadisticasagropecuarias- $2 /$

INIAP. (2011). Manejo integrado del cultivo del maíz suave. En: Módulos de Capacitación para Capacitadores. Seguridad y Soberanía alimentaria basada en la producción de sana de alimentos, Seguridad y Soberanía alimentaria basada en la producción de sana de alimentos, módulo IV.

Kambhampati, S., \& Smith, P. (1995). PCR primers for the amplification of four insect mitochondrial gene fragments. Insect Molecular Biology, 4(4), 233-236. https://doi.org/10.1111/j.1365-2583.1995.tb00028.x

Levy, H.C., García-Maruniak, A. \& Maruniak, J. E. (2002). Strain identification of Spodoptera frugiperda (Lepidoptera: Noctuidae) insects and cell line: PCRRFLP of cytocrome oxidase c subunit I gene. Florida Entomologist, 85(1), 186-190. https://doi.org/10.1653/00154040(2002)085[0186:SIOSFL]2.0.CO;2

Lima, M., Silva, P., Oliveira, O., Silva, K. \& Freitas, F. (2010). Corn yield response to weed and fall armyworm controls. Planta Daninha, 28(1), 103-111. http://dx.doi.org/10.1590/S0100-83582010000100013

Lunt, D., Zhang, D., Szymura, J. \& Hewitt, G. (1996). The insect cytochrome oxidase I gene: evolutionary patterns and conserved primers for phylogenetic studies. Insect Mol. Biol, 5(3), 153-165. https://doi.org/10.1111/j.1365-2583.1996.tb00049.x

Murua, M., \& Virla, E. (2004). Presencia invernal de Spodoptera frugiperda (Smith) (Lepidoptera: Noctuidae) en el área maicera de la provincia de Tucumán, Argentina. Revista de la Facultad de Agronomía, 105(2), 46-52. http://hdl.handle.net/10915/15677

Pastrana, J., \& Hernandez, J. (1979). Clave de orugas de lepidópteros que atacan al maíz en cultivo. RIA. Serie 5. Patología Vegetal, 79(1), 26-45.

PIONEER. (2014). Manejo de gusano cogollero en cultivos de maíz. Retrieved from https://www.pioneer.com/cmroot/international/argentin a_intl/agronomia/manejo_de_gusano_cogollero_en_ma iz.pdf

Pogue, M. (2002). A world revision of the genus Spodoptera Guenée (Lepidoptera: Noctuidae) Memories American Entomological Institut, 43, 1-202.

Saldamando, C., \& Marquez, E. (2012). Aproximación a la filogenia de Spodoptera (Lepidoptera: Noctuidae) con el uso de un fragmento del gen del citocromo oxidasa I (COI). Revista de Biología Tropical, 60(3), 1237-1248. https://doi 10.15517/rbt.v60i3.1775

Sambrook, J. \& Rusell, D. (2001). Molecular cloning. A laboratory manual, Cold Spring Harbor Laboratory Press. $3^{a}$. Ed. New York, 1885 pp.

Sparks, A. (1979). A review of the biology of the fall armyworm. Florida Entomologist, 62(2), 82-87. Retrieved from http://journals.fcla.edu/flaent/article/view/57356

Valarezo, O., Cañarte, E., Navarrete, B., \& Muñoz, X. (2010). Manejo integrado de las principales plagas del Maíz. INIAP, Plegable Divulgativo, 389, 1-10.

Vélez-Arango, A., Arango, R., Villanueva, M., Aguilera, D., \& Saldamando C. (2008). Identificación de biotipos 
de Spodoptera frugiperda (Lepidoptera: Noctuidae) mediante marcadores mitocondriales y nucleares.

Revista Colombiana de Entomología, 34(2), 145-150 